\title{
Comparative analysis of energy potential of three ways of configuration of a condenser power plant thermal cycle
}

\author{
Tadeusz Chmielniak, Prof. \\ The Silesian University of Technology \\ Piotr Krzyślak, Assoc. Prof. \\ Gdańsk University of Technology
}

\begin{abstract}
A theoretical, comparative analysis of three configuration ways of a condenser power plant thermal cycle is shown in the work. A new regeneration \& separation preheater and its application in a thermal cycle is presented. Results obtained allow to compare all three analysed configurations efficiencies.
\end{abstract}

Keywords: Comparative analysis of energy, condenser, power plant, thermal cycle, new regeneration, separation preheater

\section{GENERAL}

A first stage of evaluation of energetic potential of a given technological proposal is to assign to it an ideal thermal cycle and to assess its efficiency.

Condenser power plants are the most common systems of electric energy production in the whole world. Elementary information how to increase their thermal efficiency is taken from an appropriate to a power plant Clausius-Rankine cycle analysis. An evolution of the cycles has reached a high level of their perfection. It does not mean that their future development is not possible. A discussion on new solutions is necessary.

Main projects lead to increase condenser power plant efficiency focus now on both live steam and feed water parameters increasing i.e. on increasing an average temperature of heat transfer into the cycle $[1,2,3]$. Another direction of the whole installation efficiency increase is an integration of exhaust gases cooling process together with regeneration system (a solution used more commonly in supercritical condenser installations for hard coal and lignites $[1,4]$ ).

In the work three ideal cycles with different regeneration process configuration are to be compared. Appropriate Rankine cycles calculations were performed for water as the cycle medium. Differences in cycles efficiency can be basis for future projects and analyses of a regeneration system assumed in the third cycle variant.

\section{CYCLES ANALYSED}

An efficiency potential of a thermal cycle operating within a water steam zone will be compared with three different solutions of the regeneration system.
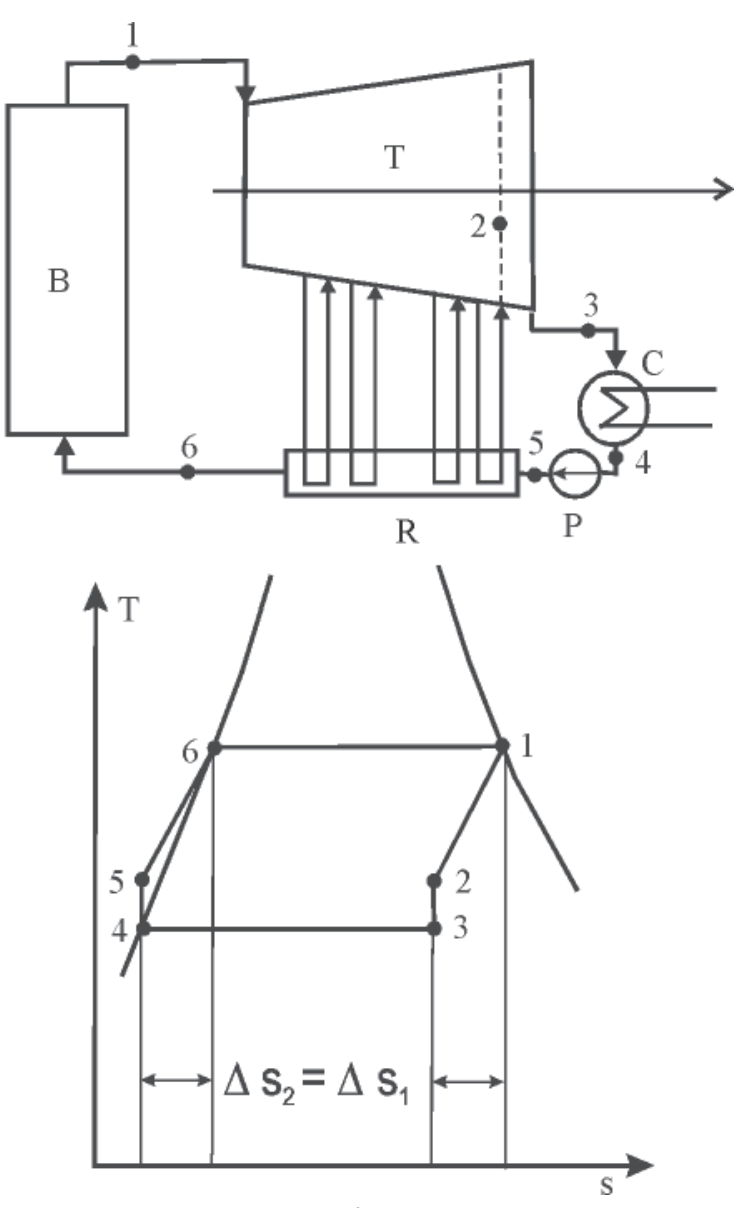

Fig. 1. CYCLE 1 diagram acc. to $[5,6]$ 
On Fig. 1 a diagram of an installation is shown to which CYCLE $1[5,6]$ is assigned. Point 1 means live steam parameters. After expansion in the first turbine part steam is directed into regeneration preheaters denominated as $\mathrm{R}$. When the steam gives back a part of its heat into the feed water it is coming back into the turbine flow path for further expansion. Such a process is repeated as many times as is preheaters number in the regeneration system $R$. The last point where the steam comes back into the regeneration system is denominated with number 2 on Fig. 1. After expansion in the last turbine part the steam flows into a condenser $\mathrm{C}$. That point is denominated as 3 . From point 4 a condensate inputs the pump $P$ and with its pressure increased is forced trough regeneration preheaters $\mathrm{R}$ and then is introduced into a boiler B. The second part of the Fig. 1 shows the cycle in T-s system. If preheaters number goes to infinity, the analysed cycle efficiency will go to Carnot cycle efficiency [6].

The following assumptions were done while analysing the cycle: expansion and pumping processes are isentropic; the whole expansion process is analysed within a wet steam zone - it comes from the above that steam initial parameters in point 1 are the same as dry saturated steam; heat transfer processes in the boiler and in preheaters $\mathrm{R}$ are isobaric. Additionally it is assumed that resistance related to heat transfer in preheaters can be neglected and from that comes that max. temperature the water heated can obtain is equal to saturation temperature of heating steam that is a function of pressure in an extraction the steam is taken from.

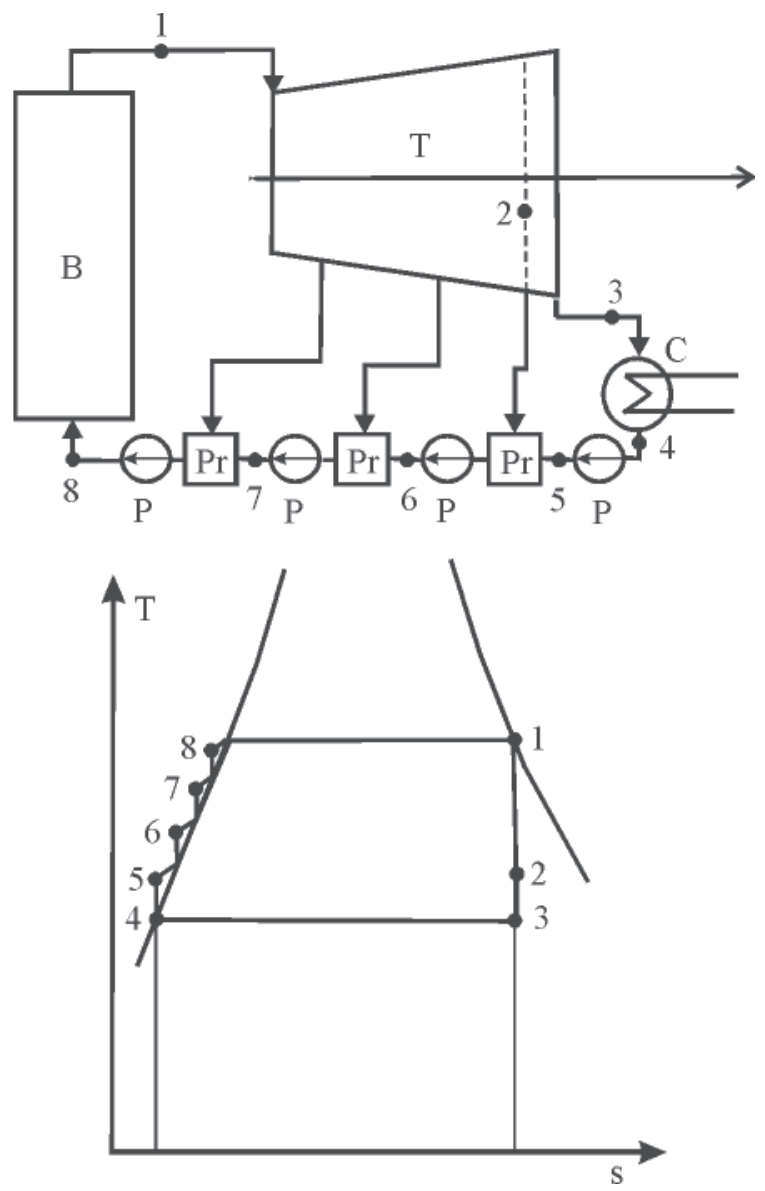

Fig. 2. CYCLE 2 diagram acc. to [6]

CYCLE 2 configuration was analysed in [7]. Whereas in the first installation membrane (direct) type preheaters were assumed, in the CYCLE 2 configuration uses no membrane (indirect) ones. The rest of assumptions is the same as for the previous configuration. In the considered configuration a pump operates after each regeneration preheater. It increases the feed water pressure to force the water or into the next preheater either into the boiler.

In CYCLE 1 configuration the medium mass flow rate is the same in each point of the cycle (in the turbine as well). In the second configuration (CYCLE 2) a situation is quite different. A steam taken from turbine extractions does not come back into the flow path but after giving its heat back into preheated water and then condensing it is together with a water flowing into the preheater forced into the next part of the regeneration system. Each next preheater (downstream the water flow) is more loaded than the previous one.

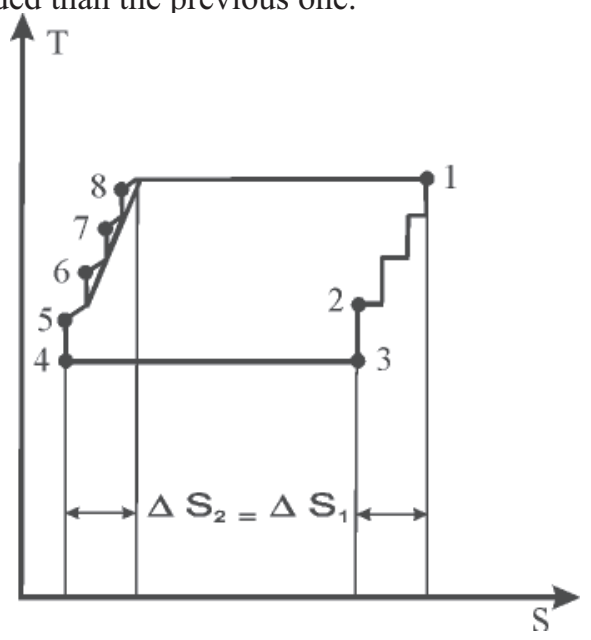

Fig. 3. Conversions for CYCLE 2 in T-S system

On Fig. 3 the process is shown on T-S diagram (S - total entropy) taking into account mass flow rate variation. Just like in the CYCLE 1 configuration the cycle efficiency goes to equivalent Carnot cycle efficiency when preheaters number goes to infinity.
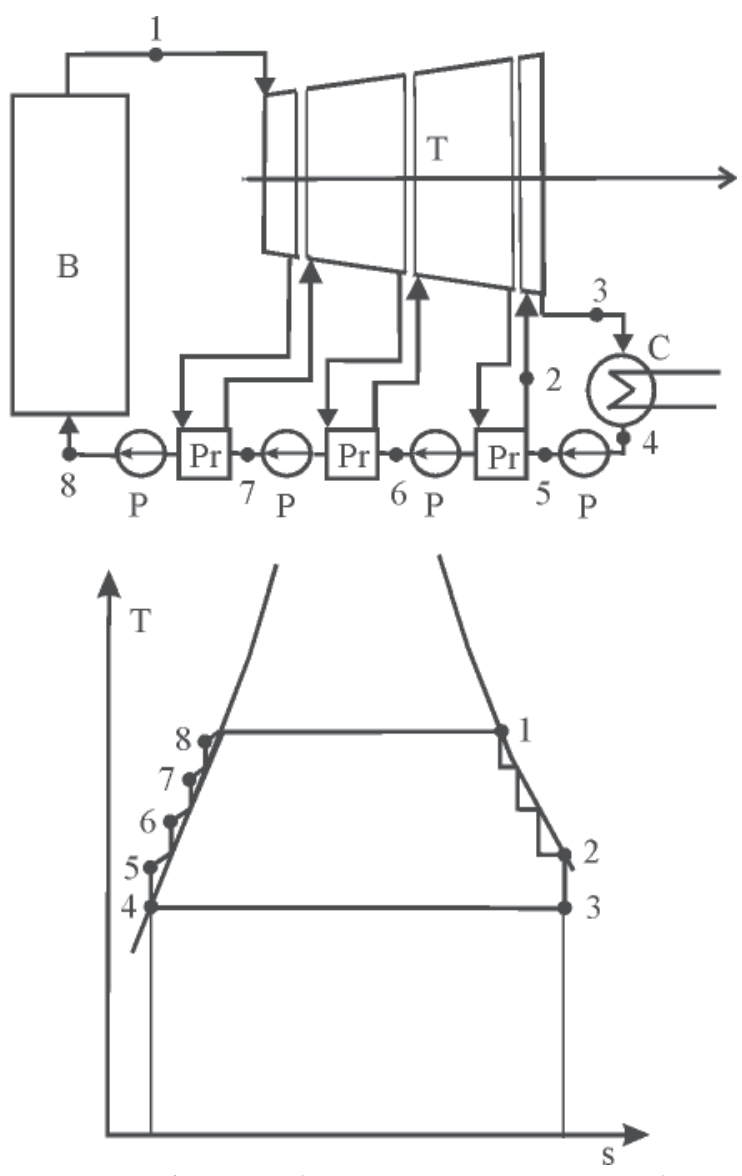

Fig. 4. CYCLE 3 diagram with regeneration \& separation preheaters [8] 
The models of two configurations shown above do not close a list of configurations with efficiency equivalent to Carnot cycle when preheaters number goes to infinity.

A cycle and direct (non membrane) heat preheater of a special type CYCLE 3 [8] were analysed in that work. In that case a regeneration \& separation preheater [8] was used that simultaneously preheats feed water and separates moisture from a steam transferred from the preheater into the turbine flow path. A diagram of the cycle with regeneration \& separation preheaters as well as processes on T-S diagram are shown on Fig. 4. After expansion in the turbine the steam inputs the preheater where gives its heat back to the feed water; additionally outdropped moisture is separated. For the whole cycle the same simplifying assumptions as for the first and the second configuration can be assumed. On Fig. 5 conception of the regeneration \& separation preheater [8] is shown in simplified form.

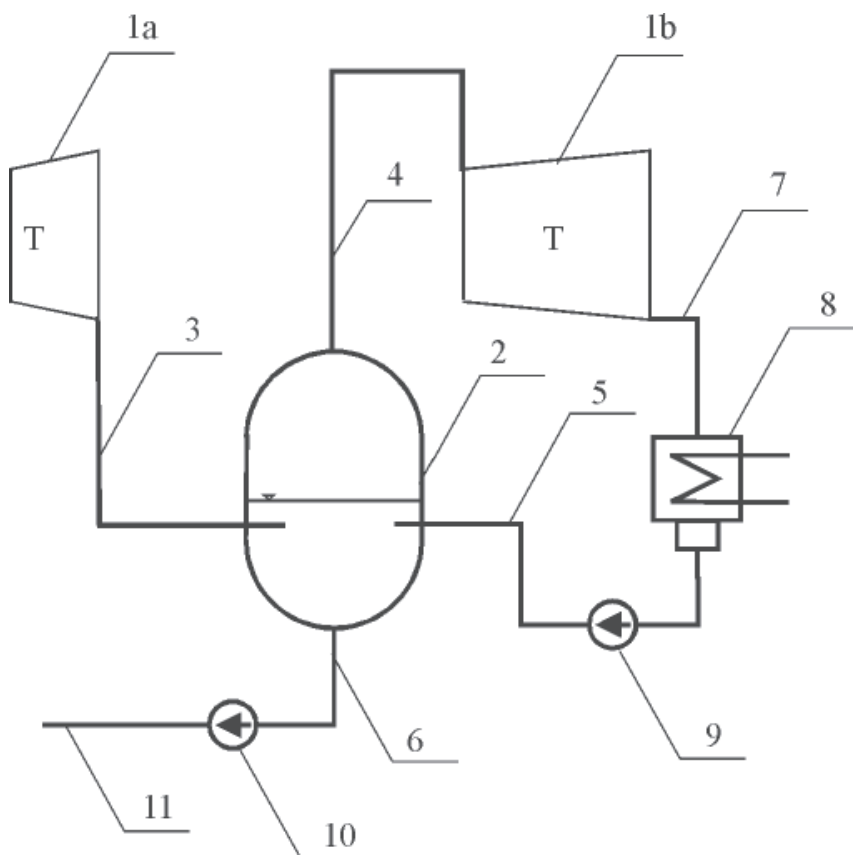

Fig. 5. Regeneration \& separation preheater diagram [8].

$\mathbf{1 a}$-steam turbine casing, $\mathbf{1 b}$ - steam turbine next casing,

2 - regeneration \& separation preheater, 3 -steam exhaust from turbine casing, 4 - saturated steam extraction from regeneration\&speparation preheater into the turbine next casing, 5 -water into regeneration \& separation preheater, $\mathbf{6}$ - condensate drain from regeneration \& separation preheater, 7 -steam exhaust into condenser, $\boldsymbol{8}$-steam condenser, 9 -condensate pump, 10 - condensate drain pump from regeneration $\&$ separation preheater, 11 - feed water pipeline into the boiler or into regeneration \& separation preheaters

\section{PARAMETRIC AND OPTIMISED CALCULATIONS OF CYCLES}

\section{Calculation models}

Taking the same assumptions allows to perform a comparative analysis of cycles efficiency for all three chosen configurations with a various regeneration preheaters number. The purpose of the analysis is to check what is a contribution of each preheater in a global effect of efficiency increase as well as to determine the regeneration configuration optimum parameters for assumed preheaters number. The calculation model for the first analysed configuration (CYCLE 1) is described with the following formulas. A single preheater model is shown on Fig. 6.

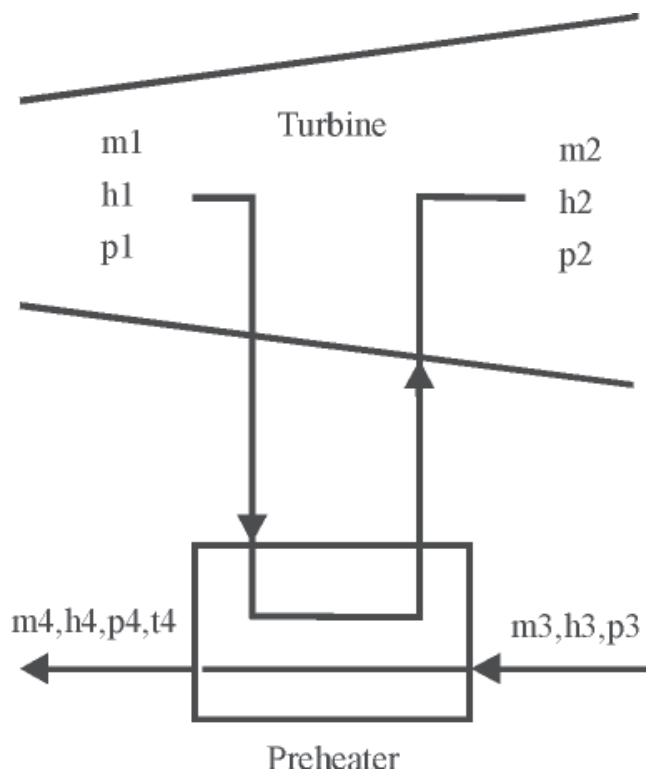

Fig. 6. Single preheater for CYCLE 1 configuration model

A mathematic model for that system was assumed as follow:

$$
\begin{gathered}
\mathrm{t} 4=\mathrm{t}_{\text {sat }}(\mathrm{p} 1) \\
\mathrm{h} 4=\mathrm{h}(\mathrm{t} 4, \mathrm{p} 3) \\
\mathrm{p} 2=\mathrm{p} 1 \\
\mathrm{~m} 2=\mathrm{m} 1 \\
\mathrm{~m} 4=\mathrm{m} 3 \\
\mathrm{p} 4=\mathrm{p} 3 \\
\mathrm{~h} 1-\mathrm{h} 2=\mathrm{h} 4-\mathrm{h} 3
\end{gathered}
$$

A final temperature $t 4$ of water preheated is determined as equal to a saturation temperature related to $\mathrm{p} 1$ pressure. The last equation describing energy balance makes possible to determine h2 enthalpy of the steam at the preheater outlet. An additional assumption is that heat ambient losses in the whole system can be neglected.

A single preheater model for CYCLE 2 configuration is shown on Fig. 7.

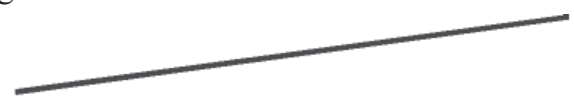

Turbine

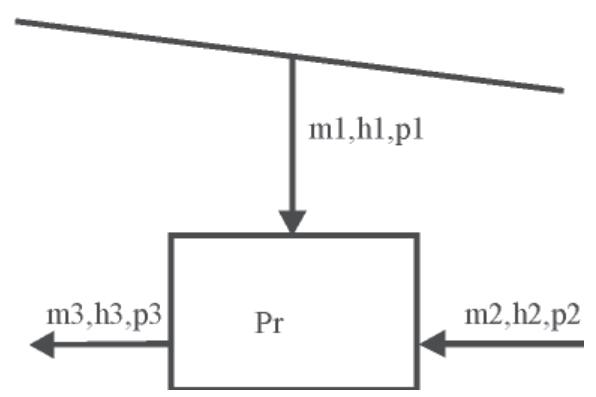

Fig. 7. Single preheater for CYCLE 2 configuration model

Processes in direct preheater (no membrane) are described with the following equations:

$$
\begin{gathered}
\mathrm{t} 3=\mathrm{t}_{\text {sat }}(\mathrm{p} 1) \\
\mathrm{h} 3=\mathrm{h}^{\prime}(\mathrm{t} 3) \\
\mathrm{p} 3=\mathrm{p} 2=\mathrm{p} 1 \\
\mathrm{~m} 3=\mathrm{m} 2+\mathrm{m} 1 \\
\mathrm{~m} 3 * \mathrm{~h} 3=\mathrm{m} 1 * \mathrm{~h} 1+\mathrm{m} 2 * \mathrm{~h} 2
\end{gathered}
$$


The last equation shows energy balance for direct preheater (no membrane) operates with a steam pressure $\mathrm{p} 1$ taken from a given extraction. It allows to calculate a mass flow of steam taken from the turbine extraction necessary to preheat water mass flow $\mathrm{m} 2$ up to enthalpy corresponding to boiling water enthalpy h'(t3).

A single preheater simplified model for CYCLE 3 configuration is shown on Fig. 8.

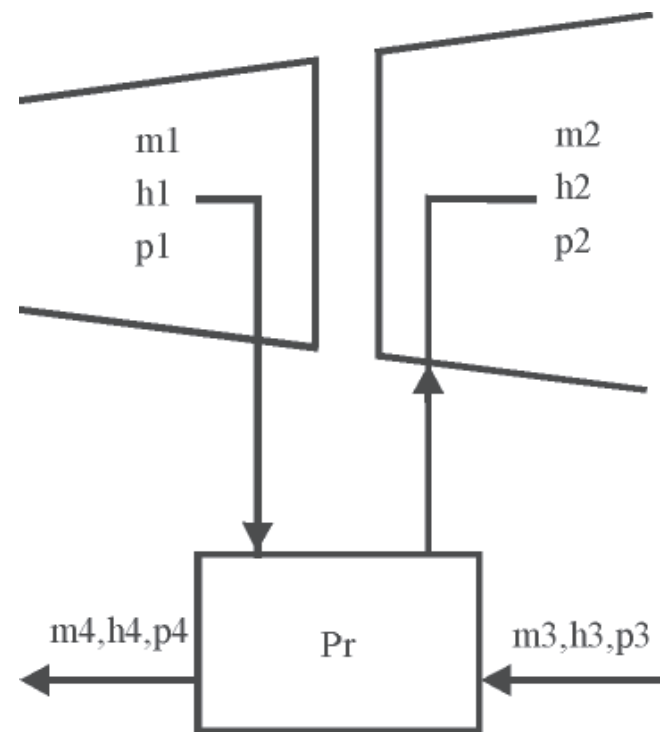

Fig. 8. Single preheater for CYCLE3 configuration model

In this case a mathematic model is as follow:

$$
\begin{aligned}
& \mathrm{t} 4=\mathrm{t}_{\text {sat }}(\mathrm{p} 1) \\
& \mathrm{h} 4=\mathrm{h}^{\prime}(\mathrm{t} 4) \\
& \mathrm{h} 2=\mathrm{h}^{\circ}(\mathrm{t} 4) \\
& \mathrm{p} 4=\mathrm{p} 3=\mathrm{p} 2=\mathrm{p} 1 \\
& \mathrm{~m} 3+\mathrm{m} 1=\mathrm{m} 2+\mathrm{m} 4 \\
& \mathrm{~m} 1 * \mathrm{~h} 1+\mathrm{m} 3 * \mathrm{~h} 3=\mathrm{m} 2 * \mathrm{~h} 2+\mathrm{m} 4 * \mathrm{~h} 4 \\
& \mathrm{~m} 3=\mathrm{m} 2
\end{aligned}
$$

In the regeneration \& separation preheater an operating pressure is the same as the pressure in the turbine extraction. The last equation describes a condition that the flow $\mathrm{m} 2$ of a steam taken from the preheater has to be the same as a flow $\mathrm{m} 3$ of water delivered into the preheater. The equation together with the energy balance one allows to determine both parameters and a mass balance in the cycle analysed.

In the CYCLE1 configuration there is one pump to increase pressure to a value corresponding the live steam pressure. In configurations CYCLE2 and CYCLE3 there are some pumps for each configuration and their number is $n+1$ where $n$ is regeneration preheaters number. All pumps have isentropic process of pressure increasing assumed that is described with the following equations:

$$
\begin{gathered}
\Delta \mathrm{p}=\mathrm{p} 2-\mathrm{p} 1 \\
\mathrm{~s} 1=\mathrm{s}(\mathrm{p} 1, \mathrm{~h} 1) \\
\mathrm{v} 1=\mathrm{v}(\mathrm{p} 1, \mathrm{~h} 1) \\
\mathrm{s} 2=\mathrm{s} 1 \\
\Delta \mathrm{h}=\mathrm{v} 1^{*} \Delta \mathrm{p} \\
\mathrm{h} 2=\mathrm{h} 1+\Delta \mathrm{h}
\end{gathered}
$$

The equations above allows to estimate water enthalpy rise in the pump while rising pressure from $\mathrm{p} 1$ at the pump suction to $\mathrm{p} 2$ at the pump discharge.

Turbine internal power is determined wit the following formula:

$$
\mathrm{N}=\sum_{\mathrm{i}=1}^{\mathrm{n}+1} \mathrm{~m}_{\mathrm{i}} * \Delta \mathrm{h}_{\mathrm{i}}
$$

where:

$\Delta \mathrm{h}_{\mathrm{i}}-$ enthalpy drop in a given stage group

$\mathrm{m}_{\mathrm{i}}-$ steam mass flow rate trough that stage group

$\mathrm{n}$ - regeneration preheaters number.

Stage group number in analysed configurations is greater by one than preheaters number $n$. Efficiency comparisons were performed for thermal cycle net efficiency i.e. thermal cycle power was determined as the turbine internal power $\mathrm{N}$ decreased by a sum of powers $\mathrm{N}_{\text {pump }}$ that is need to drive all pumps in the analysed cycle.

$$
\mathrm{N}_{\text {net }}=\mathrm{N}-\sum \mathrm{N}_{\text {pump }}
$$

Heat stream inputted into a cycle $\mathrm{Q}_{\text {in }}$ was determined as a product of a steam in the boiler mass flow rate and steam enthalpy difference at the boiler inlet and outlet. Then the efficiency can be defined with the following formula:

$$
\eta=\frac{\mathrm{N}_{\text {net }}}{\mathrm{Q}_{\text {in }}}
$$

In all calculations water and steam properties were taken in acc. to [9]. For all analysed configurations the live steam pressure was assumed as 120 bar(a) and a pressure in the condenser was assumed as 0.05 bar(a).

Pressures of both live steam and steam in the condenser allow to determine respectively both max. and min. temperatures in the thermal cycle. In that case Carnot cycle efficiency is $\eta_{\mathrm{c}}=0.488$.

\section{Calculation results}

For assumed constant regeneration preheaters number both water preheated in subsequent preheaters and the final preheating temperature of the feed water before the boiler significantly influence on the cycle efficiency. Calculations were performed in variants with feed water into the boiler temperature various. On Fig. 9 results of calculations of CYCLE1 efficiency vs. feed water temperature and number of preheaters $n$ are shown. On Fig. 10 and Fig. 11 similar results for CYCLE2 and CYCLE3 respectively are shown.

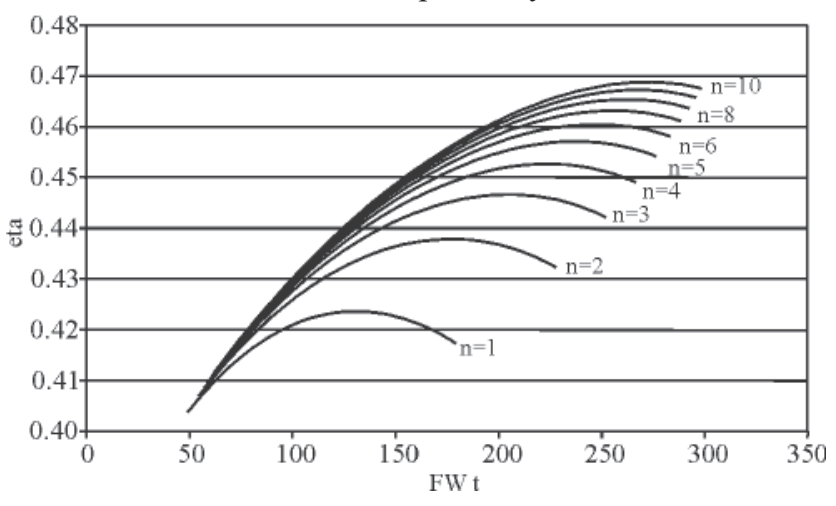

Fig. 9. CYCLE1 efficiency vs. FW temperature ( $\left.t_{F W}\right)$ and number of preheaters $n$

In all analysed cases an optimum feed water temperature for a given preheaters number fulfils the following inequalities:

$$
\mathrm{t}_{\mathrm{FW}, \mathrm{CYCLE} 3}>\mathrm{t}_{\mathrm{FW}, \mathrm{CYCLE} 2}>\mathrm{t}_{\mathrm{FW}, \mathrm{CYCLE} 1}
$$




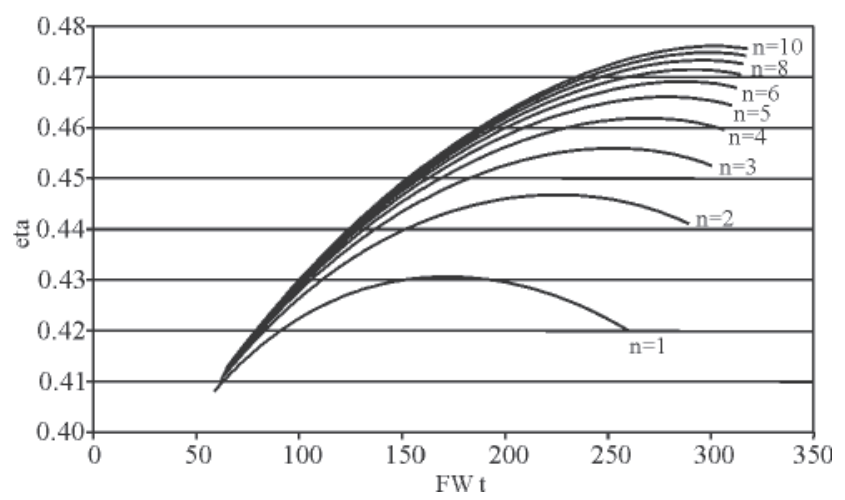

Fig. 10. CYCLE2 efficiency vs. FW temperature $\left(t_{F W}\right)$ and number of preheaters $n$

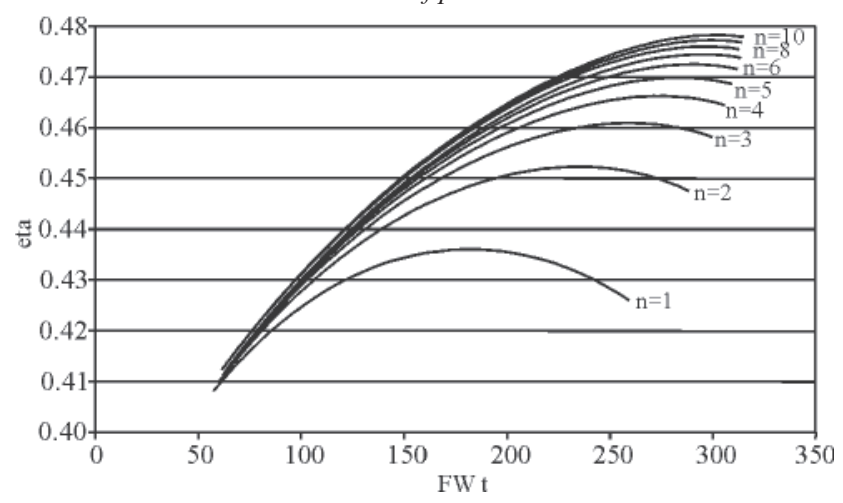

Fig. 11. CYCLE3 efficiency vs. FW temperature $\left(\boldsymbol{t}_{F W}\right)$ and number of preheaters $n$

Quantitative relations can be seen on Figs 12 to 14 . When preheaters number increases, differences for CYCLE2 and 3 for optimum $\mathrm{t}_{\mathrm{FW}}$ values are small.

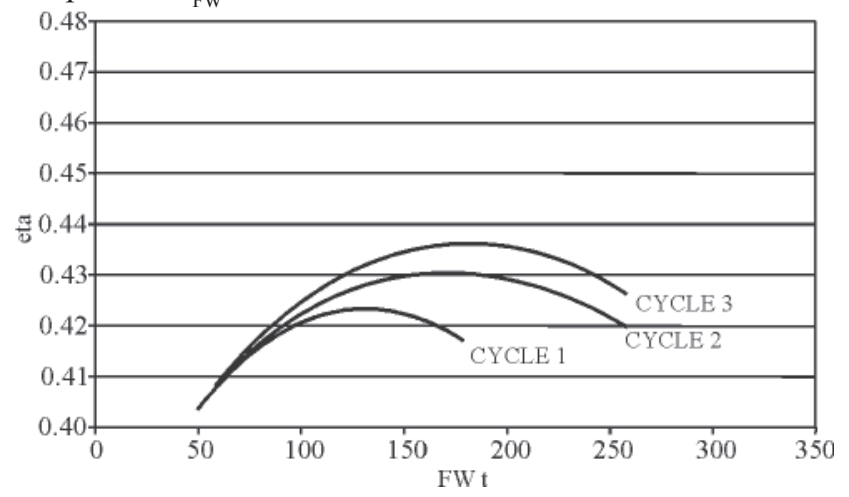

Fig. 12. CYCLE 1, 2, 3 comparison for preheaters number $n=1$

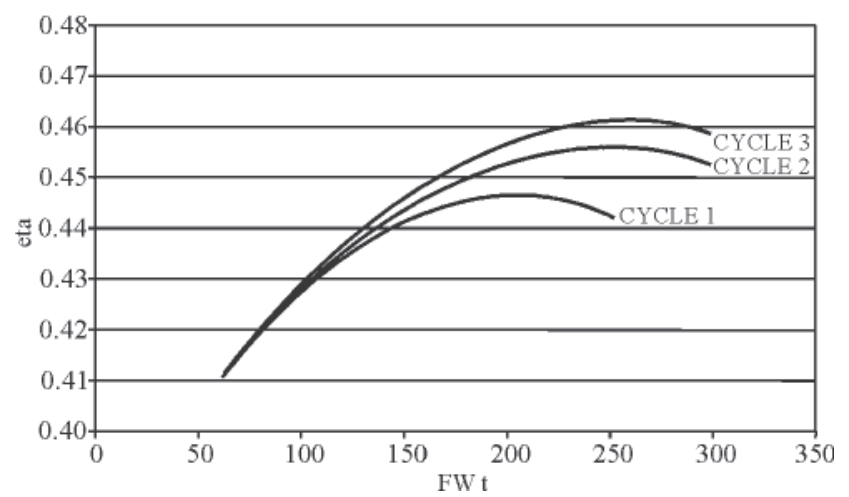

Fig. 13. CYCLE 1, 2, 3 comparison for preheaters number $n=3$

Max. efficiencies set-up for all three compared cycles is shown on Fig. 16.

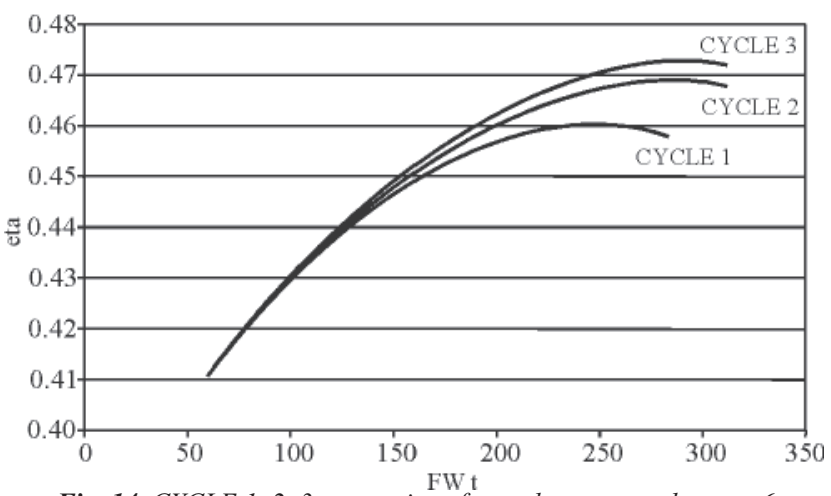

Fig. 14. CYCLE 1, 2, 3 comparison for preheaters number $n=6$

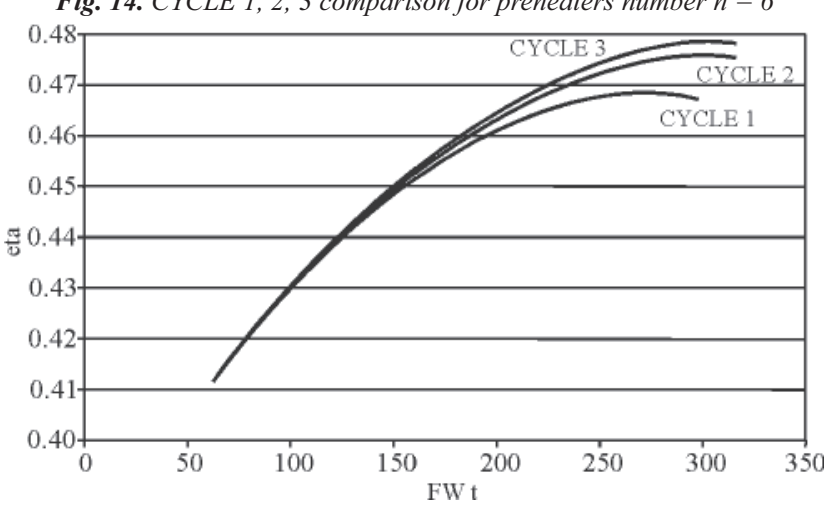

Fig. 15. CYCLE 1, 2, 3 comparison for preheaters number $n=10$

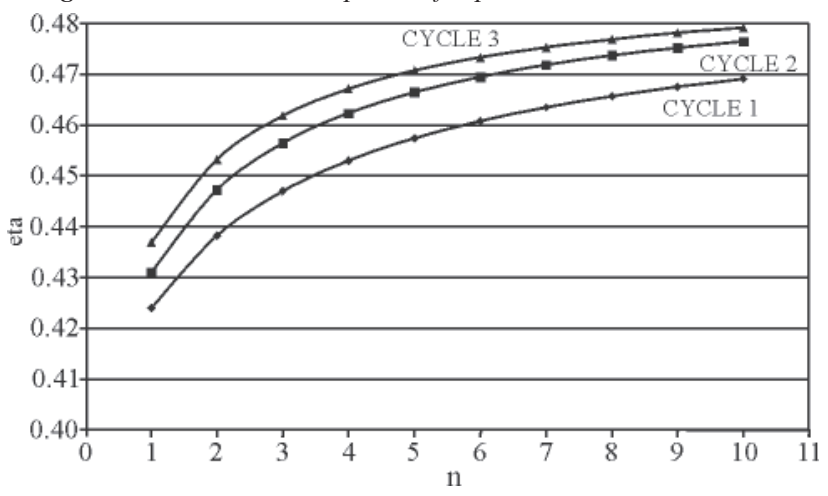

Fig.16. CYCLE 1, 2, 3 efficiencies vs. preheater number $n$

On Fig. 17 differences between CYCLE 3 \& CYCLE 1 and between CYCLE $2 \&$ CYCLE 1 are shown. Differences in an optimum of feed water temperature suggests that efficiency differences of the cycles analysed are caused by both a change of an average temperature of heat transfer into a cycle and entropy generation in a heat transfer process in the regeneration system. Using a cycle entropy analysis an identification of such influences was performed.

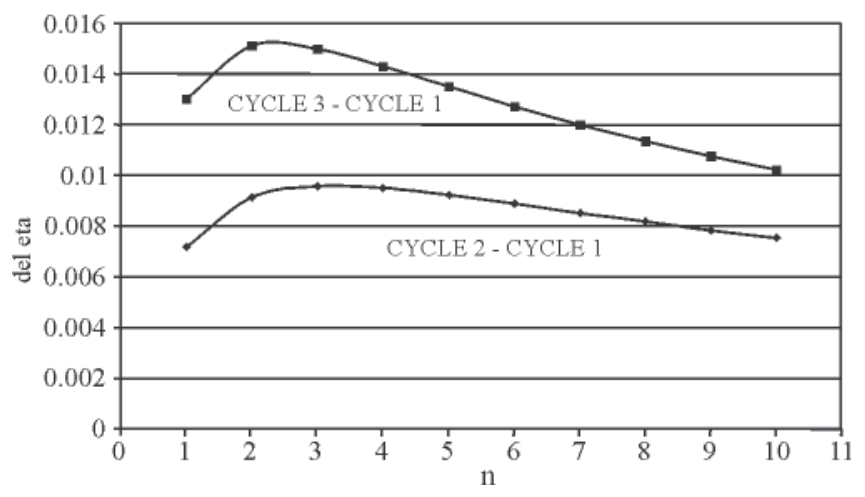

Fig. 17. Differences between CYCLE 3 \& CYCLE 1 and between CYCLE 2 \& CYCLE 1. 


\section{ENTROPY ANALYSIS}

For the general diagram shown on Fig. 18 that encloses all analysed process structures it can be written as follow $[10,11]$ :

$$
\begin{gathered}
\mathrm{Q}_{\text {in }}-\mathrm{Q}_{\text {out }}-\mathrm{Q}_{\mathrm{amb}}=\mathrm{N}_{\mathrm{b}}-\mathrm{N}_{\text {inneed }}=\mathrm{N}_{\text {net }} \\
\frac{\mathrm{Q}_{\text {out }}}{\overline{\mathrm{T}}_{\text {out }}}-\frac{\mathrm{Q}_{\text {in }}}{\overline{\mathrm{T}}_{\text {in }}}-\mathrm{S}_{\mathrm{amb}}=\mathrm{S}_{\text {sys }}
\end{gathered}
$$

where:

$\mathrm{Q}_{\text {in }}, \mathrm{Q}_{\text {out }}$ - relevant heat streams into and out of the cycle $\mathrm{N}_{\text {inneed }} \quad$ - internal needs within a balance shield

$\overline{\mathrm{T}}_{\text {in }}, \overline{\mathrm{T}}_{\text {out }}[\mathrm{K}]$ - entropy averaged temperature of heat transfer into and out of the cycle

$\mathrm{Q}_{\mathrm{amb}} \quad-$ heat stream into environment

$\mathrm{S}_{\mathrm{amb}} \quad-$ entropy generation due to heat transfer with environment

$\mathrm{S}_{\mathrm{sys}} \quad-$ entropy generation in the system.

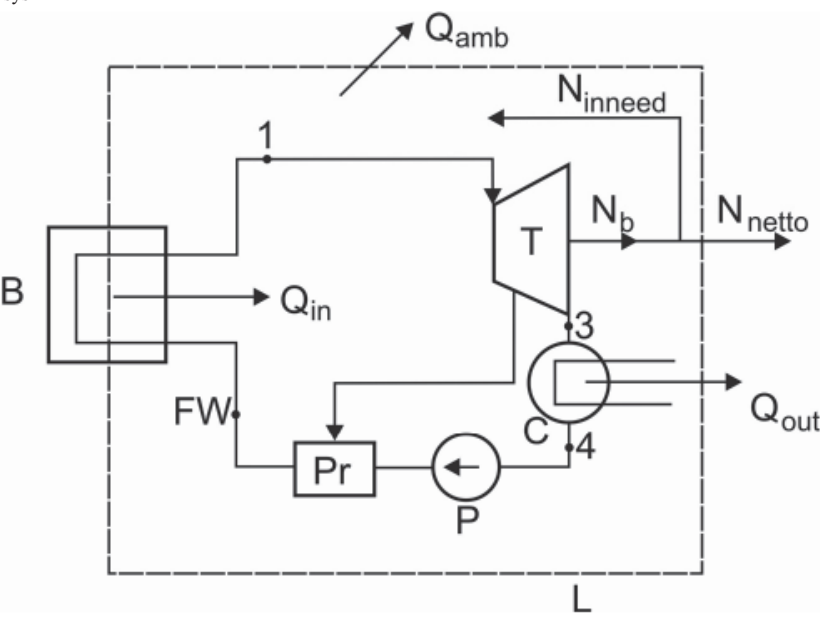

Fig. 18. Diagram for formulas (1) (2) deriving.

$\boldsymbol{B}$ - boiler, $\boldsymbol{P r}$ - regeneration system, $\boldsymbol{C}$ - condenser, $\boldsymbol{P}$ - pump

$\boldsymbol{T}$-turbine, $\boldsymbol{F} \boldsymbol{W}$-feed water, $\boldsymbol{L}$ - balance shield

The following relates to descriptions given on Fig. 18:

$$
\begin{gathered}
\overline{\mathrm{T}}_{\text {in }}=\frac{\mathrm{Q}_{\text {in }}}{\mathrm{m}_{\text {in }}\left(\mathrm{s}_{1}-\mathrm{s}_{\mathrm{FW}}\right)}, \mathrm{Q}_{\text {in }}=\mathrm{m}_{\text {in }}\left(\mathrm{h}_{1}-\mathrm{h}_{\mathrm{FW}}\right) \\
\overline{\mathrm{T}}_{\text {out }}=\frac{\mathrm{Q}_{\text {out }}}{\mathrm{m}_{3}\left(\mathrm{~s}_{3}-\mathrm{s}_{4}\right)}, \mathrm{Q}_{\text {out }}=\mathrm{m}_{3}\left(\mathrm{~h}_{3}-\mathrm{h}_{4}\right)
\end{gathered}
$$

Assuming that $\mathrm{Q}_{\mathrm{amb}}=0$, then:

$$
\begin{gathered}
\eta=\frac{N_{b}-N_{\text {inneed }}}{Q_{\text {out }}}=\frac{N_{\text {net }}}{Q_{\text {in }}}= \\
=\frac{\overline{\mathrm{T}}_{\text {in }}-\overline{\mathrm{T}}_{\text {out }}}{\overline{\mathrm{T}}_{\text {in }}}\left(1-\frac{\overline{\mathrm{T}}_{\text {in }} \overline{\mathrm{T}}_{\text {out }}}{\overline{\mathrm{T}}_{\text {in }}-\overline{\mathrm{T}}_{\text {out }}} \frac{\mathrm{S}_{\text {sys }}}{\mathrm{Q}_{\text {in }}}\right)=\bar{\eta}_{\mathrm{c}} \eta_{\mathrm{j}}
\end{gathered}
$$

where:

$$
\begin{gathered}
\bar{\eta}_{\mathrm{c}}=\frac{\overline{\mathrm{T}}_{\text {in }}-\overline{\mathrm{T}}_{\text {out }}}{\overline{\mathrm{T}}_{\text {in }}} \\
\eta_{\mathrm{j}}=1-\frac{\overline{\mathrm{T}}_{\text {in }} \overline{\mathrm{T}}_{\text {out }}}{\overline{\mathrm{T}}_{\text {in }}-\overline{\mathrm{T}}_{\text {out }}} \frac{\mathrm{S}_{\text {sys }}}{\mathrm{Q}_{\text {in }}}=1-\frac{\overline{\mathrm{T}}_{\text {out }} \mathrm{S}_{\text {sys }}}{\bar{\eta}_{\mathrm{c}} \mathrm{Q}_{\text {in }}}
\end{gathered}
$$

$\mathrm{m}$ - mass flow rate.
The $\bar{\eta}_{c}$ efficiency is Carnot machine efficiency that operates between entropy averaged temperatures of heat transfer into and out of the cycle; $\eta_{j}$ - is a measure of perfection of equipment in the cycle. In the considered case, when compression and expansion processes are isentropic and heat transfer is isobaric, $\eta_{j}$ is a measure of egzergy losses in the heat transfer process as well as in mixing process in regeneration preheaters.

To compare $\bar{\eta}_{\mathrm{c}}$ and $\eta_{\mathrm{j}}$ for the cycles analysed configurations with four regeneration preheaters and optimum feed water temperature were chosen. The analysis results are shown in table 1.

Tab. 1.

\begin{tabular}{|c|c|c|c|c|c|c|}
\hline Item & Config. & $\bar{\eta}_{\mathbf{c}}$ & $\begin{array}{c}\mathbf{S}_{\text {sys }} \\
{[\mathbf{k W} / \mathbf{d e g}]}\end{array}$ & $\boldsymbol{\eta}_{\mathbf{j}}$ & $\bar{\eta}_{\mathbf{c}} \eta_{j}=\eta$ & $\boldsymbol{\eta}_{\mathbf{j}} \boldsymbol{\eta}_{\mathbf{c}}$ \\
\hline 1 & CYCLE 1 & 0.473 & 0.1163 & 0.957 & 0.453 & 0.928 \\
\hline 2 & CYCLE 2 & 0.483 & 0.1064 & 0.956 & 0.462 & 0.947 \\
\hline 3 & CYCLE 3 & 0.485 & 0.0865 & 0.963 & 0.467 & 0.957 \\
\hline
\end{tabular}

It results from the table that for the considered configurations of the regeneration system, entropy averaged heat inlet temperatures are almost the same for CYCLE 2 and CYCLE 3 (temperatures $\bar{T}_{\mathrm{W}}$ are the same for all appropriate configurations). It is due to small difference between values of feed water optimum temperatures for CYCLE 2 and CYCLE 3 configurations. The first cycle (CYCLE 1) has the highest absolute energy losses in regeneration preheaters whereas CYCLE 2 configuration has the lowest value of $\eta_{j}$ efficiency. It comes from different heat amount introduced into CYCLE 1 and CYCLE 2. High efficiency $\bar{\eta}_{\text {f }}$ for that cycle (CYCLE 2 ) causes that its total efficiency is higher then CYCLE 1 efficiency. In the third cycle both $S_{g}, S_{g} / Q_{d}$ ratio have the smallest values what in connection with high efficiency $\bar{\eta}_{\mathrm{c}}$ leads into the highest efficiency $\eta=\bar{\eta}_{\mathrm{c}}$ $\eta_{\mathrm{j}}$. It should be noted that formulas (1) and (4) give the same values of efficiency.

\section{REMARKS AND CONCLUSIONS}

The most important result of the analysis performed is a statement that for different cycle configurations different efficiencies can be obtained with finite regeneration preheaters number. Whereas for all three analysed cycles a top limit is Carnot cycle efficiency (when preheaters number goes to infinity) that for finite preheaters number considerable differences in efficiency are obtained. Figures from 12 to 15 show that CYCLE 3 configuration is always more efficient than CYCLE 2 or CYCLE 1 within the whole area of feed water into the boiler temperature changes. It comes from Fig. 16 that CYCLE 3 configuration efficiency is 0.46 with only three regeneration \& separation preheaters whereas to obtain the same efficiency with CYCLE1 configuration it has to be used six preheaters. It is essential from the turbine flow path point of view. Each turbine extraction is a place where the steam flow is disturbed. Decreasing extractions number without any losses for the cycle allows the turbine efficiency increase.

As it can be seen from comparison showed on Fig. 17 within the whole range of the analysis (from $n=1$ to $n=10$ of regeneration preheaters) CYCLE 2 gives $0.7 \%$ efficiency increase in relation to CYCLE 1 whereas CYCLE 3 gives more than $1 \%$ efficiency increase respectively.

The results obtained encourage to further regeneration \& separation preheater analysis. Such a preheater can be used 
in both conventional and nuclear power plants although in nuclear plants an area of its application can be much wider. It shall be noted that for CYCLE 3 configuration the highest steam dryness can be obtained, higher than for CYCLE 1 and CYCLE 2.

The work presented is performed as a theoretical analysis but results obtained show at a necessity to look for both new condenser power plant cycle configurations and new equipment that can make possible to increase efficiency [ 3 , 8]. The analysis is a base for choosing regeneration systems development directions.

Good characteristics of the regeneration \& separation preheater obtained for model conditions have not to be directly transferred to cycles with real processes. Their suitability shall be verified by appropriate thermodynamic and economic analyses.

\section{BIBLIOGRAPHY}

1. Chmielniak T., Lewandowski J.: Rooms for improvement of the thermodynamic imperfection of processes of supplying with the electricity (in. Analysis of the possibility of reducing the thermodynamic imperfection of processes of supplying the sustainable development of the country in the aspect with the electricity, the warmth and coolness. Ed.: A. Ziębik, J. Szargut, W. Stanek). The IV department of Technological Sciences you, Committee of the Thermodynamics and burning, Warsaw 2006

2. Chmielniak T., Kosman G.: Problems of the development of steam turbines for high parameters of steam. Committee of Problems of Energetics you. Set of papers of the Seminar: Essential Problems of Machines and Energy Devices. Jabłonna, 27-28.03.2003

3. Krzyślak P.: New conceptions of increase in the efficiency of thermal cycles with steam turbines of the great power. Ed. of the Poznań technical university, series of Trial 401, Poznań 2006
4. Zabłocki W.: Energy blocks with pots about parameters the nadkrytycznych as the prospect of the future in the modernization and the development of the Polish power industry. Committee of Problems of Energetics you. Set of papers of the Seminar: Essential Problems of Machines and Energy Devices. Jabłonna, 27-28.03.2003

5. Haywood K.W.: Analysis Engineering Cycles of. Pergamon Press, Oxford, New York, Toronto, Sydney, Braunschweig 1975

6. Chmielniak T.: thermodynamic Circulations of heat turbines. Ossolineum, Wrocław 1988

7. Szargut J.: Thermodynamics. WNT, Warsaw 2004

8. Application for a patent. The way and the arrangement of the regeneration of the thermal cycle of the steam turbine. P 381640, patent office 2007

9. Wagner in., Kruse and.: Properties of water Steam and (IFC 97). Springer Verlag, Berlin 1997

10.Chmielniak T.: Measures of the evaluation of the thermodynamic effectiveness of thermal fitness rooms. The Warsaw Technical University. Scientific works - z.6 Conferences, 1995

11.Łukowicz H.: Rates of the decline of elements of thermal fitness rooms based on analysis of the generation of the entropy. Archive of Energetics, XXXIV volume, 2, 2005.

\section{CONTACT WITH AUTHORS}

Piotr Krzyślak, Assoc. Prof.

Faculty of Mechanical Engineering

Gdansk University of Technology

Narutowicza 11/12

80-952 Gdansk, POLAND

e-mail : pkrzysla@pg.gda.pl

Tadeusz Chmielniak, Prof.

Institute of Measurements and Automatic Control

in Electrical Engineering

The Silesian University of Technology

Konarskiego 18

44-100 GLIWICE, POLAND

e-mail: tadeusz.chmielniak@polsl.pl

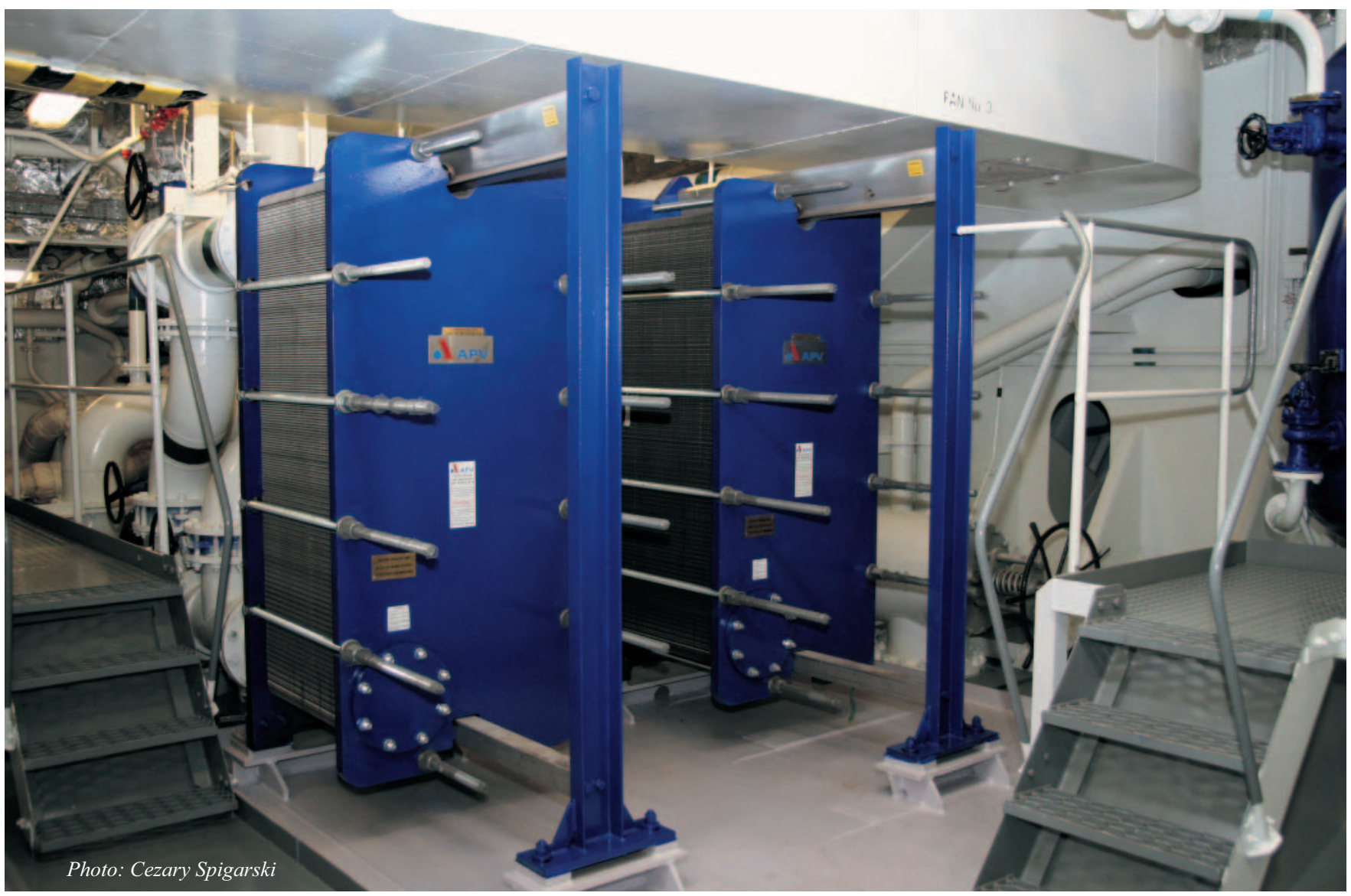

